\title{
From the Editor's Perspective
}

\author{
Theofanis Fotis PhD, MSc, BSc, RN
}

I $\mathrm{t}$ is at this time of the year, during the first weeks of January that we take the time to review what we have achieved during the past year and make plans for the new one.

There are many challenges ahead for all health-care professionals and especially for nurses of all specialties. One of these challenges will be the human resources management of these professionals, under the pressure of the global financial crisis. This pressure has been studied by many researchers and the effects on employees have been published in several journals [World Health Organization (WHO), 2007, 2009]. A financial crisis follows a pattern that starts with a Trust crisis followed by a classical overproduction crisis, economic crisis, which at the end leads to social crisis where the people are affected. The fact is that all employees will be affected to some extent. Many of the symptoms that people display in relation to these crises stem from a growing sense of frustration, uncertainty, disappointment and ineffectiveness and a sense of losing control. These symptoms are often described as increasing tiredness, confusion and malaise. They can also include feeling punch-drunk with too many problems to solve; a feeling of personal isolation from family and friends at home and work; a sense of inadequacy in family life due to lack of time/ money to maintain former lifestyles; a personal dilemma between the temptation to quit or give in to despair, or the courage or 'bottle' it takes to hang on and keep trying [Williams, 2008]. These effects will definitely have an impact on the employee's morale and productivity.

These problems will have to be dealt with by ward managers. However, it is inevitable due to a lack of experience or an unwillingness to face these problems, that administrative staff will usually only see the tip of the iceberg, when at the same time the bigger problem is hiding below the surface. We cannot afford not to deal with these issues if we want to keep our patients safe and the quality of the health-care services we offer, at the highest level.

Managerial staff should be alert to the fact that these issues will increase in the future and that they should prepare themselves to react and resolve them. This is particularly true with critical care areas such as the Anaesthesia department, and the post-anaesthetic care unit, where the needs and condition of the patient are critical. Staff within these clinical areas should have a clear mind, isolated from these external psychological effects, so that they can focus on the monitoring of and care for their patients.

There are a number of papers within the literature that deal with such subjects either from a health-care perspective or from the point of view of other disciplines, such as psychology and business administration. We should seek information within the literature to prepare ourselves and be alert for early recognition of such symptoms among our staff.

Despite the fact that the situation we face here in the United Kingdom is not the same as in other European countries, it does not mean that we should not be prepared for the unexpected. It is important that we learn from our nursing colleagues from around the globe. As the sharing of knowledge and also experience, is key towards not only healthy staff, but also healthy patients.

\section{REFERENCES}

Williams D (2008). Psychological effects of the UK recession, 1990-94. Discussion papers on psychology and society.

World Health Organization (WHO) (2007). Impact of economic crises on mental health. The consequences of financial stress for individuals, families, and society. Retrieved 8 January 2013 from http://www.euro.who.int/_data/ assets/pdf_file/0008/134999/e94837.pdf

WHO (2009). Impact of financial crisis on health: a truly global solution is needed. Retrieved 8 January 2013 from http://www.who.int/mediacentre/ news/statements/2009/financial_crisis_ 20090401/en/index.html 